\title{
ANALISIS PENENTUAN PENGARUH HAMBATAN SAMPING AKIBAT AKTIVITAS TATA GUNA LAHAN DI JALAN TANJUNG DUREN DAN TAMAN DAAN MOGOT
}

\author{
Muhamad Reza Alviana' dan Najid ${ }^{2}$ \\ ${ }^{\text {I} P r o g r a m ~ S t u d i ~ S a r j a n a ~ T e k n i k ~ S i p i l, ~ U n i v e r s i t a s ~ T a r u m a n a g a r a, ~ J l . L e t ~ J e n d ~ S ~ P a r m a ~ N o ~ 1, ~ J a k a r t a ~ B a r a t ~}$ \\ Email: bathia.dharma@gmail.com \\ ${ }^{2}$ Program Studi Sarjana Teknik Sipil, Universitas Tarumanagara, Jl.Let Jend S Parma No 1, Jakarta Barat \\ Email: Najid2009@yahoo.com;
}

\begin{abstract}
ABSTRAK
Kemacetan lalu lintas adalah salah satu masalah yang selalu ada di daerah ibukota khususnya jakarta. Seperti terlihat pada ruas Jalan Tanjung Duren Raya dan Taman Daan Mogot Raya (200m) yang menjadi salah satu contoh ruas yang mengalami kemacetan .Dalam studi ini hambatan samping sangat berpengaruh pada kinerja lalu lintas, karena semakin tinggi hambatan samping akan berpengaruh terhadap volume kendaraan ,dan kecepatan kendaraan .Data yang di gunakan untuk mengetahui hambatan samping tersebut adalah dengan cara mengitung jumlah hambatan samping, volume lalu lintas,kecepatan rata-rata kendaraan dan tata guna lahan untuk mengetahui hambatan tersebut harus diadakan survey dan mengolah data hasil survey dengan cara Pearson Correlation ,agar dapat mengetahui hambatan yang paling berpengaruh pada volume dan kecepatan kendaraan. Diperoleh korelasi paling erat yaitu korelasi antara hambatan samping dengan pengakses jalan dengan $\mathrm{R}=0,82$ pada sore hari dijalan Taman Daan Mogot Raya.
\end{abstract}

Kata kunci :Hambatan Samping, Kemacetan, Volume Kendaraan

\section{PENDAHULUUAN}

\section{Latar Belakang}

Hambatan samping merupakan aktivitas samping jalan yang sering menimbulkan dampak terhadap kinerja lalu lintas, seperti pejalan kaki, pedagang kaki lima, kendaraan umum/kendaraan lain berhenti, kendaraan masuk dan keluar pada aktivitas guna lahan sisi jalan, dan kendaraan lambat. Hambatan di tepi jalan tersebut sering kali terkait dengan adanya aktivitas sosial dan ekonomi, dengan contoh seperti adanya kendaraan parkir di badan jalan yang dikarenakan terdapat pertokoan yang tidak menyediakan tempat parkir, sarana angkutan umum yang menurunkan penumpang disembarang tempat serta lalu lalangnya orang untuk menyeberang yang menyebabkan kapasitas jalan mengalami penurunan. Salah satu penyebab tingginya aktivitas samping jalan yaitu disebabkan oleh perkembangan aktivitas penduduk yang setiap tahunnya tumbuh dan berkembang di wilayah perkotaan. Perkembangan aktivitas peduduk berpengaruh besar terhadap fasilitas dan pemenuhan kebutuhan namun hal tersebut belum diimbangi oleh penyediaan sarana dan prasarana transportasi yang memadai sehingga munculnya permasalahan transportasi pada ruas jalan perkotaan. Pergerakan lalu lintas muncul karena adanya pemenuhan suatu kebutuhan. Kebutuhan manusia dapat terpenuhi apabila dengan cara melakukan pergerakan dan terjadinya suatu pergerakan membutuhkan moda transportasi (sarana) dan sistem jaringan jalan (prasarana) karena itu tingginya pergerakan lalu lintas harus didukung sistem jaringan jalan yang mencukupi sehingga tidak terjadi hambatan

\section{Tujuan Penelitian}

1. Menganalisis nilai hambatan samping yang memiliki tata guna lahan yang berbeda.

2. Menyusun korelasi antara tata guna lahan dengan nilai parameter hambatan samping.

3. Mengevaluasi kategori kelompok hambatan samping.

\section{Hambatan Samping}

Hambatan samping adalah dampak terhadap kinerja lalu lintas yang berasal dari aktivitas samping segmen jalan. Banyaknya aktifitas samping jalan sering menimbulkan berbagai konflik yang sangat besar pengaruhnya terhadap kelancaran lalu lintas. Tingkatan hambatan samping dikelompokan dalam lima kelas, dari kelas rendah sampai kelas tinggi sebagai fungsi dan kejadian hambatan samping disepanjang jalan yang diamati. Hambatan samping yang umumnya sangat mempengaruhi kapasitas jalan yaitu, pejalan kaki, kendaraan parkir dan berhenti, 
kendaraan masuk dan keluar sisi jalan, kendaraan lambat. Aktifitas pejalan kaki merupakan salah satu faktor yang dapat mempengaruhi nilai kelas hambatan samping, terutama pada daerah-daerah yang merupakan kegiatan masyarakat seperti pusat-pusat perbelanjaan. Banyak jumlah pejalan kaki yang menyebrang atau berjalan pada samping jalan dapat menyebabkan laju kendaraan menjadi terganggu. Hal ini semakin diperburuk oleh kurangnya kesadaran pejalan kaki untuk menggunakan fasilitas-fasilitas jalan yang tersedia, seperti trotoar dan tempat-tempat penyeberangan. Kurang tersedianya lahan parkir yang memadai bagi kendaraan dapat menyebabkan kendaraan parkir dan berhenti pada samping jalan. Pada daerah-daerah yang mempunyai tingkat kepadatan lalu lintas yang cukup tinggi, kendaraan parkir dan berhenti pada samping jalan dapat memberikan pengaruh terhadap kelancaran arus lalu lintas. Banyaknya kendaraan masuk/keluar pada samping jalan sering menimbulkan berbagai konflik terhadap arus lalu lintas perkotaan. Pada daerah-daerah yang lalu lintasnya sangat padat disertai dengan aktifitas masyarakat yang cukup tinggi, kondisi ini sering menimbulkan masalah dalam kelancaran arus lalu lintas. Dimana arus lalu lintas yang melewati ruas jalan tersebut menjadi terganggu yang dapat mengakibatkan terjadinya kemacetan. Yang termasuk dalam kendaraan lambat adalah becak, gerobak dan sepeda. Laju kendaraan yang berjalan lambat pada suatu ruas jalan dapat menggaggu aktifitas-aktifitas kendaraan yang yang melewati suatu ruas jalan. Oleh karena itu kendaraan lambat merupakan salah satu faktor yang dapat mempengaruhi tinggi rendahnya nilai kelas hambatan samping.

\section{Tata Guna Lahan/Tanah}

Menurut Jayadinata (1986), tata guna tanah (land use) adalah pengaturan penggunaan tanah. Dalam tata guna tanah dibicarakan bukan saja mengenai penggunaan permukaan bumi di daratan, tetapi juga mengenai penggunaan permukaan bumi di lautan.

Menurut Vink (1975), setiap bentuk campur tangan (intervensi) manusia terhadap lahan dalam rangka memenuhi kebutuhan hidupnya baik material maupun spiritual.

Pasal 2 Peraturan Pemerintah Republik Indonesia No 16 Tahun 2004 berbunyi "Penatagunaan tanah beraasaskan keterpaduan, berdayaguna dan berhasilguna, serasi, selaras, seimbang, berkelanjutan, keterbukaan, persamaan, keadilan dan perlindungan hukum". Yang betujuan untuk mengatur penguasaan, penggunaan dan pemanfaatan tanah bagi berbagai kebutuhan kegiatan pembangunan yang sesuai dengan Rencana Tata Ruang Wilayah serta mewujudkan penguasaan, penggunaan dan pemanfaatan tanah agar sesuai dengan arahan fungsi kawasan dalam dengan Rencana Tata Ruang Wilayah.

\section{Kecepatan}

Menurut Hobbs, F.D., (1995), kecepatan merupakan laju perjalanan yang biasanya dinyatakan dalam kilometer per jam (km/jam) dan umumnya dibagi 3 jenis.

1. Kecepatan setempat (spot speed), yaitu kecepatan kendaraan pada suatu saat diukur dari suatu tempat yang ditentukan,

2. Kecepatan bergerak (running speed), yaitu kecepatan kendaraan rata-rata pada suatu jalur pada saat kendaraan bergerak dan didapat dengan membagi panjang jalur dibagi dengan lama waktu kendaraan bergerak menempuh jalur tersebut

3. Kecepatan perjalanan (journey speed), kecepatan efektif kendaraan yang sedang dalam perjalanan antara dua tempat, dan merupakan jarak antara dua tempat dibagi dengan lama waktu bagi kendaraan untuk menyelesaikan perjalanan antara dua tempat tersebut, dengan lama waktu ini mencakup setiap waktu berhenti yang ditimbulkan oleh hambatan (tundaan) lalu lintas.

\section{Kapasitas Jalan}

Menurut (MKJI 1997), kapasitas jalan adalah penilaian pada orang atau barang masih cukup layak dalam kemampuannya memindahkan sesuatu. Menurut Peraturan Menteri Perhubungan No: KM 14 Tahun 2006, "Kapasitas jalan adalah kemampuan ruas jalan untuk menampung volume lalu lintas ideal per satuan waktu, dinyatakan dalam kendaraan/jam atau satuan mobil penumpang (smp)/jam." Kapasitas dapat diartikan juga sebagai arus lalu lintas maksimum yang dapat lewat pada waktu tertentu dengan kondisi yang ditetapkan. Faktor-faktor yang mempengaruhi kapasitas jalan antara lain kondisi geometri, kondisi lalu lintas, kondisi lingkungan.

\section{C = Co x FCw $\times$ FCsp $\times$ FCsf $\times$ FCcs}


Keterangan :

$\mathrm{C}=$ Kapasitas $(\mathrm{smp} / \mathrm{jam})$

Co $=$ Kapasitas dasar (smp/jam)

$\mathrm{FCw}=$ Faktor penyesuaian lebar jalan

FCsp = Faktor penyesuaian pemisahan arah (hanya untuk jalan tak terbagi)

FCsf = Faktor penyesuaian hambatan samping dan bahu jalan/kereb

FCcs $=$ Faktor penyesuaian ukuran kota

\section{METODOLOGI PENELITIAN}

Agar pelaksanaan penelitian efektif dan efisien, diperlukan metodologi penelitian yang runtut. Sehingga setiap tahap kegiatan yang dilakukan dapat lebih terarah untuk mencapai tujuan dan hasil yang diharapkan. Langkah penelitian adalah sebagai berikut:

Tahap I $\quad$ : Penetapan Tujuan, Metode Pengumpulan dan Analisis

Tahap II : : Identifikasi Masalah

Tahap III : Penentuan Lokasi

Tahap IV : : Pembuatan Fomulir Survey

Tahap V : : Perbaikan Formulir Survey

Tahap VI : : Pengambilan Data

Tahap VII $\quad$ : Kompilasi Data

Tahap VIII : Kesimpulan dan Saran

Adapun Metode yang digunakan dalam penulisan skripsi ini adalah:

1. Metode pengumpulan data sekunder (literatur dan data instasional) dan analisis data sekunder

2. Metode survei lapangan dengan langsung menghitung jumlah kendaraan tidak bermotor, kendaraan parkir, orang menyeberang jalan, jumlah akses per 200 meter ruas jalan yang bersangkutan, tata guna lahan pada masing-masing jalan yang diteliti.

\section{Metode Pengumpulan Data}

Metode survei dengan observasi lapangan dilakukan per 200 meter pada jalan yang di teliti. Dalam 200 meter tersebut data yang diambil adalah volume lalu lintas, kecepatan lalu lintas dan jumlah hambatan samping. Data volume lalu lintas yang diteliti adalah jumlah sepeda motor, jumlah mobil, jumlah bus dan jumlah truk. Untuk mendapatkan kecepatan, di lapangan kita mendapatkan data waktu tempuh suatu kendaraan dalam jarak 100 meter. Jarak dibagi dengan waktu tempuh maka kita akan mendapatkan kecepatan dalam m/s. Hambatan samping dihitung berdasarkan masing-masing jenis hambatan sampingnya.

\section{ANALISIS}

\section{Analisis Data}

Metode analisis data yang digunakan adalah metode statistik terutama metode korelasi Pearson.

\section{Kompilasi Data}

Kompilasi data terdiri dari:

1. Volume lalu lintas

2. Kecepatan lalu lintas

3. Hambatan samping

\section{Hubungan Tata Guna Lahan dan Hambatan Samping}

Dilakukan perbandingan antara jenis tata guna lahan dengan masing-masing jenis hambatan samping untuk melihat jenis tata guna lahan yang memiliki jumlah hambatan samping paling besar. 
Tabel 1 Hubungan Tata Guna Lahan dan Hambatan Samping

\begin{tabular}{|c|c|c|c|c|c|c|}
\hline Jalan & $\begin{array}{c}\text { Jenis Tata Guna } \\
\text { Lahan }\end{array}$ & Waktu & $\begin{array}{l}\text { Kendaraan } \\
\text { Tidak } \\
\text { Bermotor }\end{array}$ & $\begin{array}{c}\text { Penyeberang } \\
\text { Jalan }\end{array}$ & Akses Jalan & $\begin{array}{l}\text { Kendaraan } \\
\text { Parkir }\end{array}$ \\
\hline \multirow{3}{*}{$\begin{array}{c}\text { Tanjung Duren } \\
\text { Raya }\end{array}$} & \multirow{3}{*}{$\begin{array}{c}12 \text { Pertokoan } \\
\text { dan } 10 \text { Tempat } \\
\text { Molan }\end{array}$} & Pagi & 7,1 & 5,075 & 147,35 & 9 \\
\hline & & Siang & 4,2 & 7,875 & 41,125 & 14,25 \\
\hline & & Sore & 3,7 & 6,475 & 196,175 & 9,5 \\
\hline \multirow{3}{*}{$\begin{array}{l}\text { Taman Daan } \\
\text { Mogot Raya }\end{array}$} & \multirow{3}{*}{$\begin{array}{c}\text { Makan, } 11 \\
\text { Rumah Kost dan } \\
\text { 2 Dartolnan }\end{array}$} & Pagi & 7,3 & 4,625 & 73,15 & 9,25 \\
\hline & & Siang & 3,9 & 3,5 & 41,3 & 10,75 \\
\hline & & Sore & 5,2 & 4,5 & 44,45 & 22,75 \\
\hline
\end{tabular}

\section{Hitungan Volume Lalu Lintas dan Hambatan Samping}

Untuk menghitung korelasi volume lalu lintas, kecepatan dengan hambatan samping digunakan rumus:

$$
R^{2}=\frac{\left\{n \sum(x y)-\sum x \sum y\right\}^{2}}{\left\{n \sum x^{2}-\left(\sum x\right)^{2}\right\}\left\{n \sum y^{2}-\left(\sum y\right)^{2}\right\}}
$$

\section{Hubungan Antara Volume, Kecepatan Rata-Rata dan Kepadatan Lalu Lintas dengan Hambatan Samping}

Hubungan volume, kecepatan dan kepadatan Lalu Lintas dengan hambatan samping di Jalan Tanjung Duren Raya dapat di lihat pada Tabel 2 di bawah ini.

Tabel 2 Hubungan Volume, Kecepatan dan Kepadatan Lalu Lintas dengan Hambatan Samping di Jalan Tanjung Duren Raya

\begin{tabular}{|c|c|c|c|c|c|c|c|c|c|c|c|}
\hline \multirow[b]{2}{*}{ Waktu } & \multirow[b]{2}{*}{$\begin{array}{c}\text { Kendaraa } \\
\text { n Tidak } \\
\text { Bermotor } \\
\text { /Lambat } \\
\text { (SMV) }\end{array}$} & \multirow[b]{2}{*}{$\begin{array}{l}\text { Penyeber } \\
\text { ang Jalan } \\
\text { (PED) }\end{array}$} & \multirow[b]{2}{*}{$\begin{array}{c}\text { Pengakse } \\
\text { s Jalan } \\
(\mathrm{EEV})\end{array}$} & \multirow[b]{2}{*}{$\begin{array}{c}\text { Kendaraa } \\
\text { n Parkir } \\
\text { (PSV) }\end{array}$} & \multicolumn{4}{|c|}{ Jumlah frekuensi berbobot } & \multirow[b]{2}{*}{ Vol (Q) } & \multirow{2}{*}{$\begin{array}{c}\mathrm{V} \\
\mathrm{rata} 2 \\
(\mathrm{~km} / \mathrm{ja} \\
\mathrm{m})\end{array}$} & \multirow[b]{2}{*}{$\begin{array}{c}\text { Kepadata } \\
\text { n (D) }\end{array}$} \\
\hline & & & & & $\begin{array}{l}\text { SMV } \\
(0,4)\end{array}$ & $\begin{array}{l}\text { PED } \\
(0,5)\end{array}$ & $\begin{array}{l}\text { EEV } \\
(0,7)\end{array}$ & $\begin{array}{c}\text { PSV } \\
(1)\end{array}$ & & & \\
\hline $07.00-07.15$ & 23 & 8 & 202 & 8 & 9,2 & 5,6 & 141,4 & 8 & 477,3 & 32 & 14,915 \\
\hline $07.15-07.30$ & 19 & 6 & 229 & 9 & 7,6 & 4,2 & 160,3 & 9 & 516 & 34 & 15,361 \\
\hline $07.30-07.45$ & 17 & 7 & 192 & 11 & 6,8 & 4,9 & 134,4 & 11 & 540,25 & 34 & 15,889 \\
\hline $07.45-08.00$ & 12 & 8 & 219 & 8 & 4,8 & 5,6 & 153,3 & 8 & 499,1 & 32 & 14,973 \\
\hline $12.00-12.15$ & 14 & 9 & 55 & 18 & 5,6 & 6,3 & 38,5 & 18 & 376,5 & 55,6 & 6,763 \\
\hline $12.15-12.30$ & 10 & 12 & 40 & 19 & 4 & 8,4 & 28 & 19 & 371,8 & 49 & 7,587 \\
\hline $12.30-12.45$ & 11 & 10 & 72 & 10 & 4,4 & 7 & 50,4 & 10 & 364,4 & 46 & 7,921 \\
\hline $12.45-13.00$ & 7 & 14 & 68 & 10 & 2,8 & 9,8 & 47,6 & 10 & 393,7 & 56,3 & 6,988 \\
\hline $17.00-17.15$ & 9 & 8 & 257 & 10 & 3,6 & 5,6 & 179,9 & 10 & 450,25 & 27,4 & 16,392 \\
\hline $17.15-17.30$ & 6 & 9 & 128 & 11 & 2,4 & 6,3 & 89,6 & 11 & 622,9 & 25,3 & 24,588 \\
\hline $17.30-17.45$ & 10 & 8 & 289 & 10 & 4 & 5,6 & 202,3 & 10 & 768,9 & 23,6 & 32,488 \\
\hline $17.45-18.00$ & 12 & 12 & 447 & 7 & 4,8 & 8,4 & 312,9 & 7 & 594,9 & 27 & 22,0333 \\
\hline
\end{tabular}


Tabel 3 Hubungan Volume Lalu Lintas dengan Hambatan Samping di Jalan Tanjung Duren Pagi Hari

\begin{tabular}{|l|c|}
\hline \multicolumn{1}{|c|}{ Vol (Q) Terhadap Hambatan Samping Di Jl. Tanjung Duren Raya Pagi Hari } & R \\
\hline Kendaraan Tidak Bermotor/Lambat & 0,227 \\
\hline Penyebrang Jalan & 0,144 \\
\hline Pengakses Jalan & 0,15 \\
\hline Kendaran Parkir & 0,78 \\
\hline
\end{tabular}

Tabel 4 Hubungan Volume Lalu Lintas dengan Hambatan Samping di Jalan Tanjung Duren Siang Hari

\begin{tabular}{|l|c|}
\hline \multicolumn{1}{|c|}{ Vol (Q) Terhadap Hambatan Samping Di Jl. Tanjung Duren Raya Siang Hari } & $\mathrm{R}$ \\
\hline Kendaraan Tidak Bermotor/Lambat & 0,137 \\
\hline Penyebrang Jalan & 0,191 \\
\hline Pengakses Jalan & 0,079 \\
\hline Kendaran Parkir & 0,12 \\
\hline
\end{tabular}

Tabel 5 Hubungan Volume Lalu Lintas dengan Hambatan Samping di Jalan Tanjung Duren Sore Hari

\begin{tabular}{|l|c|}
\hline \multicolumn{1}{|c|}{ Vol (Q) Terhadap Hambatan Samping Di Jl. Tanjung Duren Raya Sore Hari } & $\mathrm{R}$ \\
\hline Kendaraan Tidak Bermotor/Lambat & 0,135 \\
\hline Penyebrang Jalan & 0,079 \\
\hline Pengakses Jalan & 0,529 \\
\hline Kendaran Parkir & 0,184 \\
\hline
\end{tabular}

Tabel 6 Hubungan Kecepatan Lalu Lintas dengan Hambatan Samping di Jalan Tanjung Duren Pagi Hari

\begin{tabular}{|l|c|}
\hline & \\
\multicolumn{1}{|c|}{ V Rata-rata Terhadap Hambatan Samping Di Jl. Tanjung Duren Raya Pagi Hari } & $\mathrm{R}$ \\
\hline Kendaraan Tidak Bermotor/Lambat & $5,1 \mathrm{E}-05$ \\
\hline Penyebrang Jalan & 0,0059 \\
\hline Pengakses Jalan & 0,002 \\
\hline Kendaran Parkir & 0,018 \\
\hline
\end{tabular}


Analisis Penentuan Pengaruh Hambatan Samping akibat

Aktivitas Tata Guna Lahan di Jalan Tanjung Duren dan

Taman Daan Mogot

Tabel 7 Hubungan Kecepatan Lalu Lintas dengan Hambatan Samping di Jalan Tanjung Duren Siang Hari

\begin{tabular}{|l|c|}
\hline \multicolumn{1}{|c|}{ V Rata-rata Terhadap Hambatan Samping Di Jl. Tanjung Duren Raya Siang Hari } & $\mathrm{R}$ \\
\hline Kendaraan Tidak Bermotor/Lambat & 0,0038 \\
\hline Penyebrang Jalan & 0,032 \\
\hline Pengakses Jalan & 0,0007 \\
\hline Kendaran Parkir & 0,018 \\
\hline
\end{tabular}

Tabel 8 Hubungan Kecepatan Lalu Lintas dengan Hambatan Samping di Jalan Tanjung Duren Sore Hari

\begin{tabular}{|l|c|}
\hline \multicolumn{1}{|c|}{ V Rata-rata Terhadap Hambatan Samping Di Jl. Tanjung Duren Raya Sore Hari } & $\mathrm{R}$ \\
\hline Kendaraan Tidak Bermotor/Lambat & 0,0045 \\
\hline Penyebrang Jalan & 0,0164 \\
\hline Pengakses Jalan & 0,0026 \\
\hline Kendaran Parkir & 0,0219 \\
\hline
\end{tabular}

Koefisien Korelasi (R) dari hasil analisis, kontribusi hambatan samping yang mempengaruhi volume lalu lintas diperoleh $(\mathrm{R})=0,78$ pada hambatan samping kendaraan parkir, hal ini menunjukan bahwa ada keeratan hubungan antara kecepatan kendaraan dengan hambatan samping tersebut. Hambatan samping lain secara bersama-sama mempengaruhi kecepatan akan tetapi kecil pengaruhnya.

Tabel 9 Hubungan Volume Lalu Lintas, Kecepatan dan Kepadatan dengan Hambatan Samping di Jalan Taman Daan Mogot Raya

\begin{tabular}{|c|c|c|c|c|c|c|c|c|c|c|c|}
\hline \multirow[b]{2}{*}{ Waktu } & \multirow{2}{*}{$\begin{array}{c}\text { Kendaraa } \\
\text { n Tidak } \\
\text { Bermotor } \\
\text { /Lambat } \\
\text { (SMV) }\end{array}$} & \multirow{2}{*}{$\begin{array}{c}\text { Penyeb } \\
\text { erang } \\
\text { Jalan } \\
\text { (PED) }\end{array}$} & \multirow{2}{*}{$\begin{array}{c}\text { Pengakse } \\
\text { s Jalan } \\
(\mathrm{EEV})\end{array}$} & \multirow{2}{*}{$\begin{array}{c}\text { Kendar } \\
\text { aan } \\
\text { Parkir } \\
\text { (PSV ) }\end{array}$} & \multicolumn{4}{|c|}{ Jumlah frekuensi berbobot } & \multirow[b]{2}{*}{ Vol (Q) } & \multirow{2}{*}{$\begin{array}{c}\text { V rata2 } \\
(\mathrm{km} / \mathrm{jam} \\
)\end{array}$} & \multirow[b]{2}{*}{$\begin{array}{c}\text { Kepadata } \\
\text { n (D) }\end{array}$} \\
\hline & & & & & $\begin{array}{l}\text { SMV } \\
(0,4)\end{array}$ & $\begin{array}{l}\text { PED } \\
(0,5)\end{array}$ & $\begin{array}{l}\text { EEV } \\
(0,7)\end{array}$ & $\begin{array}{c}\text { PSV } \\
(1)\end{array}$ & & & \\
\hline $07.00-07.15$ & 15 & 11 & 109 & 8 & 6 & 5,5 & 76,3 & 8 & 386,15 & 34,6 & 11,138 \\
\hline $07.15-07.30$ & 19 & 7 & 125 & 12 & 7,6 & 3,5 & 87,5 & 12 & 392,05 & 33,1 & 11,844 \\
\hline $07.30-07.45$ & 19 & 9 & 79 & 10 & 7,6 & 4,5 & 55,3 & 10 & 405,2 & 39,03 & 10,38 \\
\hline $07.45-08.00$ & 20 & 10 & 105 & 7 & 8 & 5 & 73,5 & 7 & 434,85 & 34,76 & 17,629 \\
\hline $12.00-12.15$ & 8 & 8 & 70 & 11 & 3,2 & 4 & 49 & 11 & 362,85 & 54,3 & 6,678 \\
\hline $12.15-12.30$ & 13 & 5 & 54 & 9 & 5,2 & 2,5 & 37,8 & 9 & 391,45 & 50,6 & 7,725 \\
\hline $12.30-12.45$ & 6 & 9 & 51 & 11 & 2,4 & 4,5 & 35,7 & 11 & 353 & 48 & 7,354 \\
\hline $12.45-13.00$ & 12 & 6 & 61 & 12 & 4,8 & 3 & 42,7 & 12 & 317,8 & 56,6 & 5,6082 \\
\hline $17.00-17.15$ & 16 & 9 & 69 & 16 & 6,4 & 4,5 & 48,3 & 16 & 514,2 & 29,16 & 17,629 \\
\hline $17.15-17.30$ & 11 & 10 & 74 & 18 & 4,4 & 5 & 51,8 & 18 & 427,3 & 32 & 13,353 \\
\hline $17.30-17.45$ & 12 & 9 & 52 & 24 & 4,8 & 4,5 & 36,4 & 24 & 412,8 & 26,46 & 15,596 \\
\hline $17.45-18.00$ & 13 & 8 & 59 & 33 & 5,2 & 4 & 41,3 & 33 & 469 & 25 & 18,513 \\
\hline
\end{tabular}


Tabel 10 Hubungan Volume Lalu Lintas dengan Hambatan Samping di Jalan Taman Daan Mogot Raya Pagi Hari

\begin{tabular}{|l|c|}
\hline \multicolumn{1}{|c|}{ Vol (Q) Terhadap Hambatan Samping Di Jl. Taman Daan Mogot Raya Pagi Hari } & R \\
\hline Kendaraan Tidak Bermotor/Lambat & 0,195 \\
\hline Penyebrang Jalan & 0,015 \\
\hline Pengakses Jalan & 0,639 \\
\hline Kendaran Parkir & 0,556 \\
\hline
\end{tabular}

Tabel 11 Hubungan Volume Lalu Lintas dengan Hambatan Samping di Jalan Taman Daan Mogot Raya Siang Hari

\begin{tabular}{|l|c|}
\hline \multicolumn{1}{|c|}{ Vol (Q) Terhadap Hambatan Samping Di Jl. Taman Daan Mogot Raya Siang Hari } & R \\
\hline Kendaraan Tidak Bermotor/Lambat & 0,031 \\
\hline Penyebrang Jalan & 0,067 \\
\hline Pengakses Jalan & 0,264 \\
\hline Kendaran Parkir & 0,513 \\
\hline
\end{tabular}

Tabel 12 Hubungan Volume Lalu Lintas dengan Hambatan Samping di Jalan Taman Daan Mogot Raya Sore Hari

\begin{tabular}{|l|c|}
\hline \multicolumn{1}{|c|}{ Vol (Q) Terhadap Hambatan Samping Di Jl. Taman Daan Mogot Raya Pagi Hari } & R \\
\hline Kendaraan Tidak Bermotor/Lambat & 0,093 \\
\hline Penyebrang Jalan & 0,07 \\
\hline Pengakses Jalan & 0,376 \\
\hline Kendaran Parkir & 0,215 \\
\hline
\end{tabular}

Tabel 13 Hubungan Kecepatan Lalu Lintas dengan Hambatan Samping di Jalan Taman Daan Mogot Raya Pagi Hari

\begin{tabular}{|l|c|}
\hline \multicolumn{1}{|c|}{ V Rata-rata Terhadap Hambatan Samping Di J1. Taman Daan Mogot Raya Pagi Hari } & R \\
\hline Kendaraan Tidak Bermotor/Lambat & 0,0012 \\
\hline Penyebrang Jalan & 0,0029 \\
\hline Pengakses Jalan & 0,0073 \\
\hline Kendaran Parkir & 0,0013 \\
\hline
\end{tabular}


Analisis Penentuan Pengaruh Hambatan Samping akibat

Aktivitas Tata Guna Lahan di Jalan Tanjung Duren dan

Taman Daan Mogot

Tabel 14 Hubungan Kecepatan Lalu Lintas dengan Hambatan Samping di Jalan Taman Daan Mogot Raya Siang Hari

\begin{tabular}{|l|c|}
\hline \multicolumn{1}{|c|}{ V Rata-rata Terhadap Hambatan Samping Di Jl. Taman Daan Mogot Raya Siang Hari } & R \\
\hline Kendaraan Tidak Bermotor/Lambat & 0,073 \\
\hline Penyebrang Jalan & 0,025 \\
\hline Pengakses Jalan & 0,407 \\
\hline Kendaran Parkir & 0,035 \\
\hline
\end{tabular}

Tabel 15 Hubungan Kecepatan Lalu Lintas dengan Hambatan Samping di Jalan Taman Daan Mogot Raya Sore Hari

\begin{tabular}{|l|c|}
\hline \multicolumn{1}{|c|}{ V Rata-rata Terhadap Hambatan Samping Di J1. Taman Daan Mogot Raya Pagi Hari } & $\mathrm{R}$ \\
\hline Kendaraan Tidak Bermotor/Lambat & 0,0032 \\
\hline Penyebrang Jalan & 0,0322 \\
\hline Pengakses Jalan & 0,8267 \\
\hline Kendaran Parkir & 0,0212 \\
\hline
\end{tabular}

Koefisien Korelasi (R) dari hasil analisis, kontribusi hambatan samping yang mempengaruhi kecepatan rata-rata lalu lintas diperoleh $(\mathrm{R})=0,826$ pada hambatan samping Pengakses Jalan, hal ini menunjukan bahwa ada keeratan hubungan antara kecepatan kendaraan dengan hambatan samping tersebut. Hambatan samping lain secara bersama-sama mempengaruhi kecepatan akan tetapi kecil pengaruhnya.

\section{KESIMPULAN}

1. Dari data yang didapat, semakin banyak hambatan samping pada sebuah jalan maka volume lalu lintas dan kecepatan lalu lintas akan semakin menurun.

2. Nilai Koefisien Korelasi (R) terbesar dari hasil analisis data menggunakan Pearson Correlation adalah 0,826 yaitu hambatan samping Pengakses Jalan pada pagi hari di Jalan Taman Daan Mogot Raya.

3. Nilai Koefisien Korelasi (R) terkecil dari hasil analisis data menggunakan Pearson Correlation adalah 0,000051 yaitu hambatan samping Kendaraan Tidak Bermotor/Lambat pada pagi hari di Jalan Tanjung Duren Raya.

4. Besarnya $\mathrm{R}$ yang mendekati nilai 0,99 dapat diartikan memiliki hubungan yang kuat antara kecepatan ratarata dan volume lalu lintas dengan hambatan samping.

5. Sebaliknya, besarnya $\mathrm{R}$ yang kecil atau mejauhi nilai 0,99 dapat diartikan memiliki hubungan yang rendah antara kecepatan rata-rata dan volume lalu lintas dengan hambatan samping, sehingga kecil pengaruhnya terhadap keadaan lalu lintas.

6. Kepadatan dengan kecepatan berbanding terbalik, artinya jika angka kepadatan meningkat maka angka kecepatan otomatis akan menurun.

\section{DAFTAR PUSTAKA}

Direktorat Jendral Bina Jalan Kota, 1997. Manual Kapasitas Jalan Indonesia. Jakarta. Kusbiantoro, B.S. (2007) Perencanaan, Pemodelan dan Rekayasa Transportasi. Bandung.

Marunseng, G .S.( 2015) Pengaruh Hambatan Samping Terhadap Kinerja Pada Ruas Jalan Panjaitan dengan Menggunakan Metode MKJI 1997.Manado.

Tamin, O . Z (2000). Perencanaan dan Pemodelan Transportasi, Edisi kedua. Jurusan Teknik Sipil Institut Teknologi Bandung, Bandung.

Wibawa, A.B. Tata Guna Lahan dan Transportasi Dalam Pembangunan Berkelanjutan. Jakarta. 